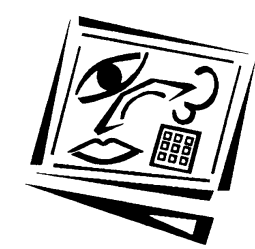

\title{
Reflections in cyberspace: Web conferencing for language teacher education
}

\author{
E. Marcia Johnson \\ The University of Waikato \\ Ann Bishop \\ Auckland, New Zealand \\ Anna Holt \\ Auckland University of Technology \\ Jennifer A. Stirling \\ University of Otago \\ Janice Zane \\ UNITEC, New Zealand
}

\begin{abstract}
This paper reports on an in depth evaluation of a distance format Applied Linguistics course in which web based computer conferencing was used as a tool to support student knowledge construction and collaborative group work. Students and their teacher reflected on what they expected from the course, whether or not computer supported discussion was effective for personal learning, and how e-learning environments could be improved. The findings are reported within categories of social cohesion and the role of online discussion to support meaningful experiential learning. More generally, the paper discusses how situated evaluation can help educators gain a better understanding of the roles of task, structure, and language use in e-learning environments.
\end{abstract}

\section{Background}

Since 1997 we have been exploring the use of computer mediated communication $(\mathrm{CMC})$ as a tool to support courses in three academic programs offered through our Applied Linguistics department at the University of Waikato in Hamilton, New Zealand. These include undergraduate courses in 'English for Academic Purposes' (EAP), and two postgraduate language teacher training programs - the Postgraduate Diploma in Second Language Teaching (PGDipSLT) and the Master of Arts (MA) in Applied Linguistics. 
Throughout our research, we have recognised the need for situated, measured evaluations of what we have implemented so that we can develop understanding from the personal perspectives of both teachers and learners (Bruce \& Peyton, 1999). As part of our on-going evaluations of how computer supported learning can be used most effectively for teaching, we are interested in considering both implicit and explicit aspects of online instruction. Of particular interest is the role that technology can play in the creation and maintenance of social relationships and the role of experiential learning in developing complex electronic literacy skills that teachers can then apply in their own language classrooms. We are also interested in our students' reactions to computer based learning environments and their evaluations of what was most effective for their own learning. Although data have been collected from a number of courses, the reflections of students and the instructor in one particular MA level course are discussed in this article.

\section{The research setting and data collection}

Both of our postgraduate language teacher education programs can be taken either full time or part time, on campus or in distance/block mode. In the on campus courses, students meet once a week with an instructor during 12-week teaching terms, which contrasts with the distance/ block courses that run throughout the academic school year (March to October). With the exception of a five day, on campus teaching week, distance students work through course materials, at their own pace, and seldom (if ever) meet face to face with the instructor or with each other once the teaching block has finished. Prior to 1997, when computer supported learning, through email and web based conferencing was introduced into many courses in the programs, distance students frequently reported feeling lonely and academically isolated.

\section{The course}

An MA level course, Language and Culture in Cyberspace, was offered in distance/ block mode from March to October, 2000. The course content focussed on issues in electronic literacy and the potential impact that computers would have in teaching and, more generally, on language and culture. On campus tuition was provided in July 2000, approximately halfway through the course, but we wanted the students to participate in web based discussions before they met both as a means of initiating a sense of group and of enriching their understanding of course content.

In addition, we were mindful that "although much of the rhetoric around online classrooms focuses on collaboration, it is important to point out that online classrooms are not necessarily collaborative in nature" (Ashton, Roberts, \& Teles, 2000, p. 1). Online course designers are guided (as are all 
teachers) by their underlying beliefs and assumptions about what constitutes good instructional practice. A key element in the course design process, then, becomes reflection on the selection and articulation of instructional tasks and learning goals - the process of course planning (Woods, 1996).

\section{The online task}

Although a variety of online collaborative tasks have been used throughout our courses (Johnson, in press), we adapted one that had been used successfully in previous, face to face offerings of the course. The task required students, on a rotating basis to locate a web based, full text journal article related to the course content, read and summarise the gist of the paper, and then post the summary (along with the appropriate URL) on the web conference. The poster was also required to develop a couple of focus questions to start online discussion. Other students had one week to locate and read the article before discussion formally began. Each student in the course was required to contribute at least two substantive comments to each online discussion, but could make as many postings as they wished. The article poster was to assume responsibility for guiding the discussion and keeping it 'on topic'. All students were expected to follow a reading and posting schedule (developed by $M$. Johnson) and $15 \%$ of their course grade was associated with this task.

\section{Course participants}

There were six students (five women and one man) in the course and all were adult learners. Four of the six (all women) were full time language teachers, each with many years of classroom based experience. The other two students (one woman and one man) were full time graduate students, but both had also worked as language teachers. In addition, three of the students were from non-native English speaking backgrounds (NESB) while the other three were native speakers of English. It is worth noting, however, that one of the NESB students had acquired such a high level of English language proficiency so as to be indistinguishable from a native speaker.

Although the number of course participants was not large, this has had the advantage of providing a rich and manageable dataset from which reflections about the nature of collaborative, knowledge-building in an online environment could be drawn.

\section{Web based conferencing software}

The university was using a web based conferencing package called Discus [http://online.waikato.ac.nz/discus/]. As is typical of web conferences, all discussions were public which meant that all participants could read 
anything written by anyone else in the course, but because access to Discus is password protected, only enrolled students could read or participate. Use of Discus is relatively straightforward for students and different discussion themes can be created, by the instructor, and tailored to the specific needs of the class. An example of the top level of one of the course discussion areas can be referenced in Figure 1.

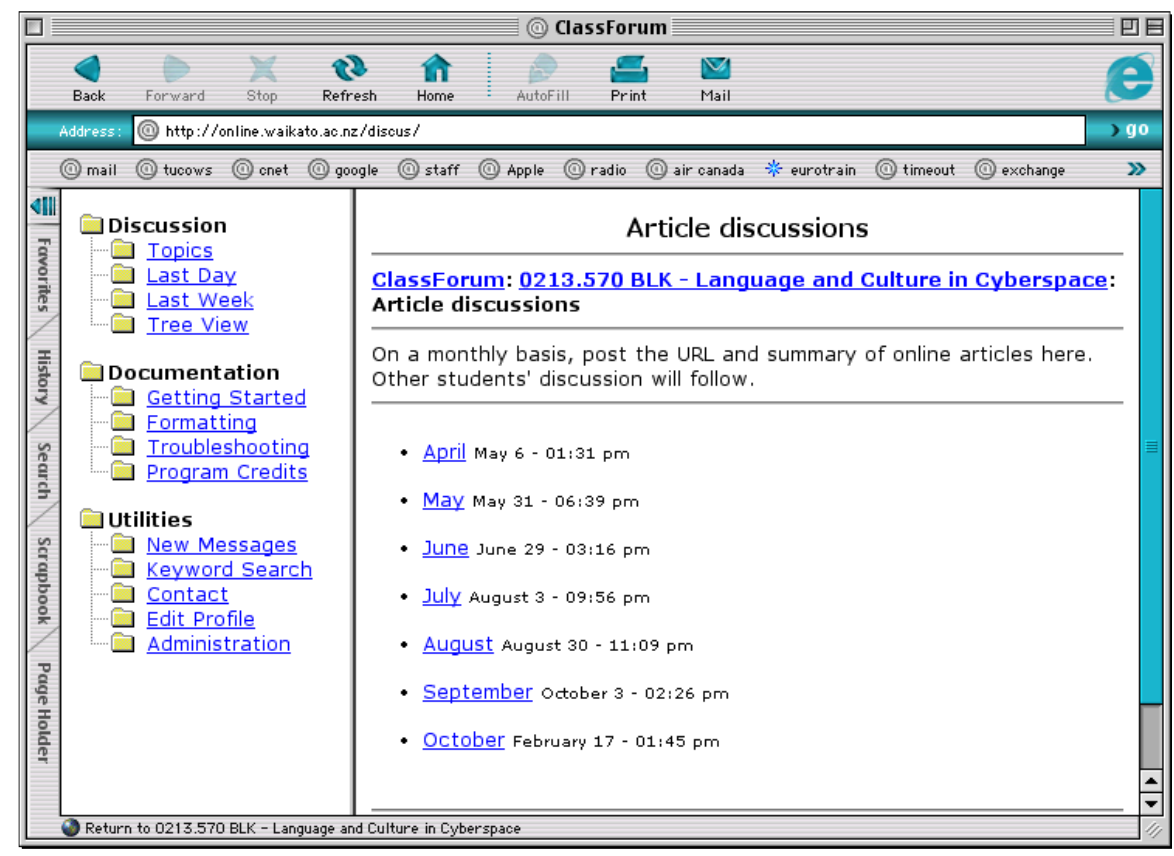

Figure 1: A top level page in the web conference (Discus)

We established five separate discussion areas for the students: assignment discussion, article discussion, class announcements, general discussion, and self introductions. Students were encouraged to use all discussion areas, but were required (as part of an assessed task) to use only one area, article discussion.

\section{Data collection and synthesis}

In this study, questionnaires, transcript analysis, and synthesis of reflections were all used so that insights gained from each individual source could be used to complement and enrich findings. Examining data from more than one source is necessary as a form of triangulation of qualitative research data (Burns, 1999; Wallace, 1998). The interaction of all 
participants in developing an understanding of their teaching and learning experiences has been a stimulating experience.

\section{Questionnaires}

Students who had completed the course were contacted by email and invited to co-author a paper; all but one agreed to participate. The students completed two separate questionnaires with the first focussing on different aspects of technology enhanced learning that they had encountered during the course, while the second elicited more general feedback on teaching and learning (during this course and elsewhere). Questionnaire items were based loosely on Palloff and Pratt's (1999, p. 158) evaluation of student satisfaction with online learning. An important distinction, however, is that this course was not fully online, but was computer supported so that there were aspects of both the online work and face to face instruction upon which we wanted students to reflect.

All students provided detailed and rich reflections in the questionnaires and their responses have been grouped according to four interrelated themes:

- personal experiential learning (including computing skills, learning styles, and course structure),

- collaboration and group knowledge building (including participation in the web conference and reactions to different instructional formats),

- features of electronic discourse (including the nature of online writing, communication, and task structure), and

- projected longer term effects on teaching and learning (including personal growth and development).

\section{Transcript analysis}

In addition to collecting students' reflections through the questionnaires, a closer examination of what had actually been written in the web conference was done through transcript analysis. Having classroom processes captured in text provides researchers with rich data sources for exploring online communicative processes, and thus transcript analysis has been used increasingly as a tool to understand, at a deeper level, the nature of online communities (Ashton, Roberts, \& Teles, 2000, p. 13). The text based transcripts of what was posted, both by the students and by M. Johnson, were synthesised into a database. As we were interested in the extent to which students had collaborated to build knowledge in their online task, the texts were read and categorised into four themes: 
- social communication (use of expressives (the type of speech act that expresses sympathy, encouragement, apologies, and so on) and social greetings),

- academic interaction (explicit reference to, and expansion upon, other students' ideas; use of explicit teaching episodes to enhance others' ideas),

- academic monologues (personal reflections and interpretation of academic articles, or critical interpretations of academic articles (but without any reference to ideas discussed by other course participants)), and

- communication about administrative issues (assignment requirements, for example) or technical computing problems.

\section{Synthesis of the data}

\section{Personal experiential learning}

Woods (1996), citing Clandinin and Connelly stated that personal practical knowledge ('images') have "strong affective connotations, and are associated with powerful beliefs and feelings about what are 'right' ways of teaching, rooted in past life experiences" (p. 192). We conjecture that if teachers have had a variety of positive experiences in computer supported learning environments, they will be far more confident, skilled, and motivated to use computers with their own language students. There were several aspect of students' learning in which we are interested including the adequacy of their background computer skills for online work, perceived changes to their approach to learning, and the effectiveness of the course structure.

Hara and Kling (2000) in their review of a computer supported course reported high levels of student frustration, at least partly because students encountered numerous technical problems, yet received little support from their instructor (who was herself a novice computer user). Although technical problems can be distressing for students, they are at a surface level and can be explicitly addressed at the outset. We prepared simple introductory documentation, with screen shots, to guide students through the process of accessing Discus and provided a number of URLs for locating additional information about computers. M. Johnson was also readily available, either through the web conference or email, to assist with solving technical problems. Even though the participants had varying levels of computer competence, this initial level of support seems to have been adequate. 
S6: The step by step instructions to getting hooked up to the online tasks were clear and it all worked well.

S5: My computer skills were really not adequate at all for the course but the course made them adequate!! That is in order to complete the course requirements I was 'forced' to develop internet skills, which I did by following the instructions provided.

Once students were online, we wanted to know if their approach to learning had been affected by using the web conference for collaborative work. Some students believed that they had changed their approach to learning, but others felt that it was their motivation to learn that had been affected.

S1: I felt I changed from being a "passive" learner into a more active one, but this may be because the level of the course was different to previous courses, Most of my university career to date had consisted of sitting in a lecture theatre writing notes, and regurgitating them at exam time. I can't ever remember ever being asked what I thought about anything.

S2: I'm sure I will continue to have to go through the same processes of learning, but having been introduced to this swift access to input from knowledgeable others has added a new dimension of excitement and anticipated engagement to my thoughts of learning in the future.... . So, basically, I feel invigorated and motivated as a learner in a new and exciting way.

The structure of the course was also a feature about which we wanted feedback - particularly the mix of learning activities, which included face to face discussions and presentations, online tasks, and 'traditional' paper based activities (academic research and writing). The course participants clearly felt that the combination of tasks had been an effective way for them to learn.

S2: I did a lot of learning through the online communication part of the course which really brought home to me some of the literacy issues which were at the heart of the course, as well as issues to do with what's going on in the mind when we interact via this mode. I would not, however, have found this effective on its own - a combination of academic writing assignments, face to face discussions, presentation and online tasks was most effective for me.

S5: I really liked the combination of delivery methods. Although I feel most comfortable with the 'traditional' paper based activities I found that there were enormous advantages to the online activities in a distance teaching course. It kept all of us in contact with what was happening at Waikato so that I continued to feel part of that University community, as well as the group. 
Having face to face interaction as a component of the course was clearly appreciated, but it is not an absolute requirement. In many courses it is not even an option. This idea will be explored in more detail in following sections.

However, using a mix of activities and providing clear organisational structures, specifying how and when task based work is to be completed, is essential. In online formats, where the teacher has no physical presence, the importance of task structure to guide and sustain teaching cannot be stressed enough. Students also believed that this was the case.

S5: I felt that it was important to have a formal structure for the online discussion task, and essential to have a definite schedule. Because this was a distance course all the students had a much wider range of other commitments than full time students. By providing a definite schedule it enabled us to integrate the demands of the discussion postings into the other varied aspects of our lives.

\section{Collaboration and group knowledge building}

In spite of the students' enthusiasm for the course, a key part of the evaluation, from our perspective, was determining whether or not they had actually worked together online to build shared knowledge, particularly since they did not meet until halfway through the course. Haythornthwaite, Kazmer, \& Robins (2000) have argued that online knowledge building tasks are much more effective if students have had a chance to actually meet face to face before beginning to work. We wanted to know if these students believed that their online interactions changed after they had met in the classroom. Most, but not all, students thought that their communication was different (improved) after they had established a personal rapport with the other class members in the classroom, but they also felt that they had participated well in online discussions even before meeting.

S6: [online participation] Personally, I was surprised at how much I enjoyed the discussion groups. This resulted in my having to be more wary of over-contributing than under-contributing. I found myself trying to hold back until others had contributed - especially as I had read the studies outlining the dilemma of having some students dominant in online discussions, just as in geographically bound groups!

S2: [after the class meeting] Having the real person in mind did give me a greater sense of having an actual discussion and helped to clarify why each group member took up a particular issue or aspect of an issue. The decisions I made about my input were affected by this to some extent. I also had a greater feeling of actually conducting a bit of a dialogue since, knowing about some of the others' personal interests and experience, I could direct some parts of my contributions directly towards these. 
More deeply we wanted to know whether or not collaborative learning and group knowledge building had actually occurred. While students seemed to appreciate and value the group interaction on an affective level, they were not entirely convinced that they had been involved in an online knowledge building community.

S6: I quickly learnt which of the others was likely to contribute items of real value. This is not to say I was dismissive of the others, but just really appreciative of some.

S5: The first few postings did not seem to have much depth of analysis and there was not much interaction. Each student - including me seemed to be reacting to the posting as an individual rather that reacting and interacting with what the others had written. However I felt that this definitely changed during the course and the discussions became more interactive and thus more meaningful.

The transcript analysis provides some illumination here with the nature of the students' online discourse being reflected in Figure 2. The overall results show that student communication was dominated by academic monologues - those episodes in which participants reflected on the content of an article, but without explicit links to ideas expressed by other contributors. The extent to which students used expressives or social language was limited as were their postings about administrative or technical problems.

ד

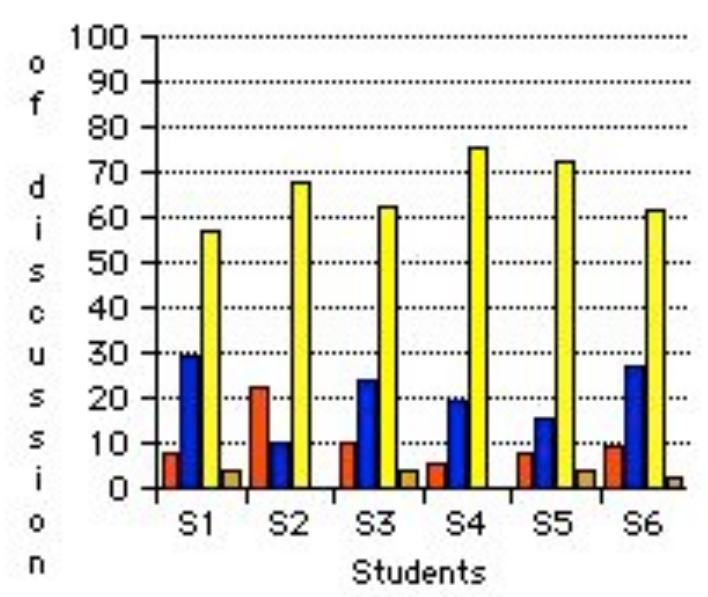

Discussion Totals - Students Only

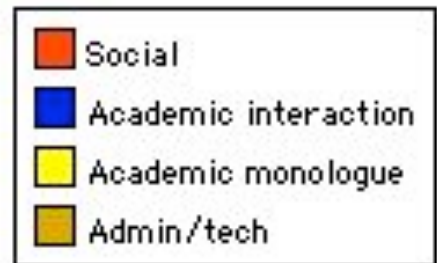

Figure 2: Overall discussion patterns of students 
However, we wanted to follow the 'hunch' of the student who felt that academic interaction had increased over the months. To this end, we compared student discussions at the beginning of the course with those in the last two months.

Figure 3 shows that 'academic monologue' dominated the communication patterns, accounting for almost $72 \%$ of the students' online writing during the first couple of months of the course, while academic interaction accounted for only $15 \%$ of the discussion.

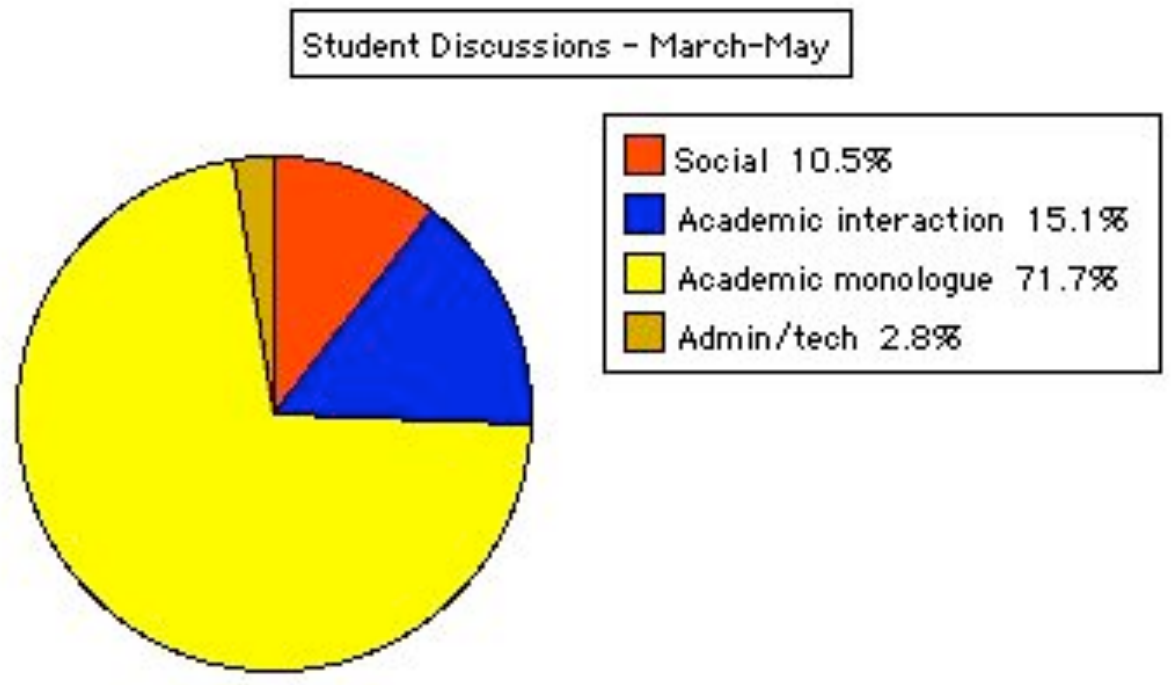

Figure 3: Students' discussions at the beginning of the course

With practice and experience, academic interaction did increase by the end of the course (Figure 4). While we concur with the students' beliefs that their in class experiences, leading as they did to a deeper sense of personal community, influenced their communications, we don't believe that the face to face meeting explained all of the change. Kern (2000: 224) in his discussion of electronic literacy states that "literacy involves familiarity with the conventions of texts - how they are arranged and structured - and knowledge of how to use those conventions to design meaning. Reading and writing electronic texts draws upon many of the same conventions used in printed texts, but also involves acquiring additional conventions that are both procedural and conceptual in nature". Consistent with the change in how students communicated from the beginning to the end of the course, we suggest that as they became more literate in this new 
medium and internalised aspects of electronic literacy, their online communication became more interactive. One of the students indicated this:

S5: Yes; I certainly found it was a lot easier to communicate after I had met the other students. However as the Block course was half way through the course there was also the factor of gaining more confidence with using the technology by that time.

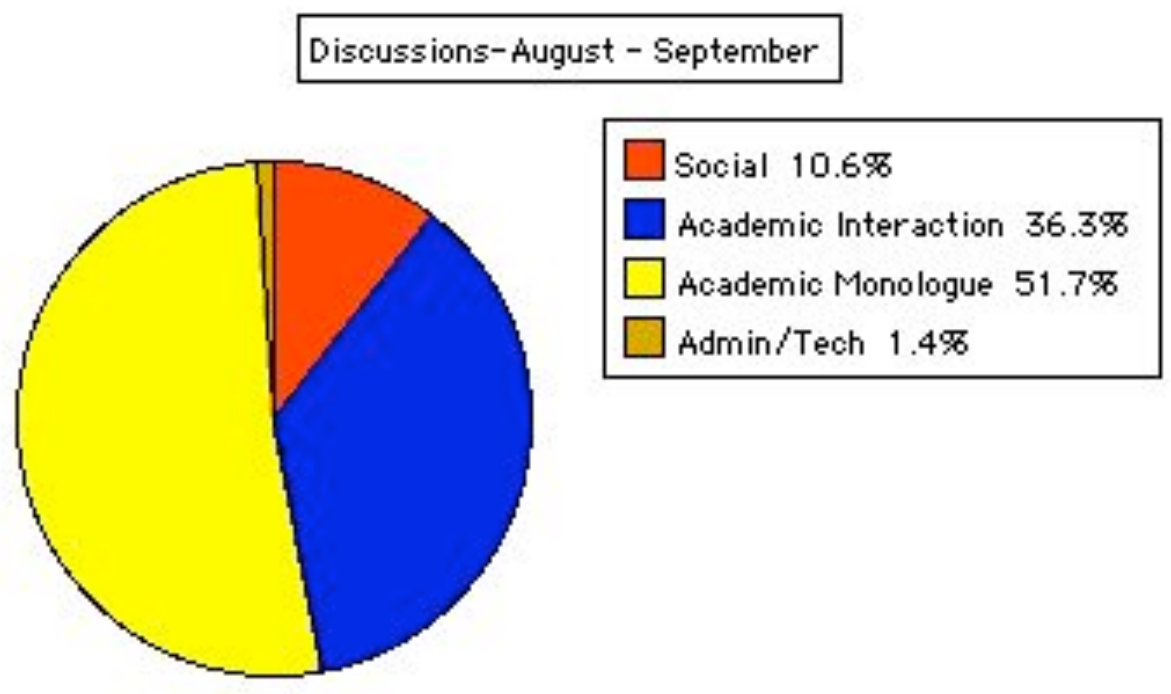

Figure 4: Students' discussions at the end of the course

\section{Issues in electronic literacy}

All students agreed that using the technology to discuss issues related to electronic literacy was highly effective and gave them insights into the types of skills that would be required in an online instructional environment. This in turn would influence their ability to teach in more a effective manner with their own students. This finding links closely into the ideas already discussed about the significance and importance of experiential learning in teacher development.

S2: We had to also apply the information literacy skills we had been reading about and discussing - not just finding the article but discriminating, analysing, evaluating. The process of doing this really illuminated the electronic literacy issues we were confronting. 
S5: Using the technology gave more relevance to the issues that were being considered. In fact I cannot imagine doing this course without using the technology. It would be rather like learning about conventional writing without knowing how to use a pen and paper.

What was also relevant was the feedback that students provided about their development of an online writing style - specifically whether or not they had modified their writing to suit the new medium. Reaction to the question was mixed; even those who felt that they had modified their style stated that their writing remained formal, not conversational, throughout the task.

S5: It [writing] was closer to formal spoken language than written language. This may have been because there was time to consider what to write so it was a bit more formal than a face-to-face discussion. Probably my writing style was closer to a formal oral presentation than academic writing.

S6: My style was less formal. This was an interesting dilemma at first, and I actually checked out style with our lecturer to ensure I was not out of line. Interestingly, as we progressed in the course, and became more engrossed in content, and more knowledgeable, I think we all became more formal.

In the case of this task, we believe that the formal nature of the students' writing has been influenced by the language used to describe the task in the course outline. By specifying a requirement for two 'substantive' comments in the task description, we may have inadvertently implied that self contained monologues were required. Although formal writing is not necessarily a problem in online writing, we believe that it did inhibit a more natural flow of ideas between course participants.

This finding points to a need for much more carefully worded task specification than one would need in the regular classroom where expectations can be clarified quickly through the exchange of spoken language. It also suggests the need to discuss student interpretations of the teacher's written language before online discussions become rooted in a particular style of interaction. Online discourse, inherently slow as it is, can become stilted. One of the students in the course suggested that more than two comments should have been required, but that each contribution should have been much shorter. This might have facilitated a more rapid exchange of ideas and might also have stimulated a more conversational writing style among contributors.

\section{Effects of course on teaching and learning}

Johnson (in press) has argued that if we want teachers to use technology in their classrooms, then students should be provided with multiple 
opportunities to use computer tools to support their own learning throughout teacher education courses. In this manner, they can gain confidence and proficiency in a variety of computing skills while experiencing different types of computer based tasks and assessment techniques. We asked students if they felt they had developed a deeper understanding of the role of technology in language teaching through their use of computers. Their feedback was positive and links into previous arguments supporting experiential learning.

S2: It is going to be impossible for educators, no matter what area of education they are in, to ignore the growing pressure to meet more and more of their students' learning needs online. By opening my eyes to what those learning needs actually are (rather than what students may think they are, e.g. just get lots of information from the net) and what the nature of the challenge is that educators face, I have been put in touch with what I will need to keep learning, where caution is called for when developing or delivering online courses, and many of the literacy issues attendant on using technology in the classroom.

An extension to the previous question was whether or not this group would be willing to use web conferencing in their own classroom teaching. Reaction was somewhat mixed, ranging from very positive to tentative. Given that the process of implementing innovations is a slow one, and involves personal change on the part of participants, this finding is not surprising.

S5: Yes I would definitely be willing to use computer supported tasks with my own second language students as I think that online communication is a very non-threatening way for students to experiment with a new language and so it can provide them with the confidence to communicate in face to face situations. The enormous advantage is that it gives them time to reflect on what they are trying to express.

S1: I teach small children, and I don't know that it would be viable for them (after all, I'm still trying to teach them to read!). In another situation, I would probably have a go - in a very limited way I think.

\section{Summary of findings}

Overall, students were very positive, in the affective domain, about using web conferencing to support their learning. Many of their comments related to feelings of participating in an academic learning community while studying at a distance. As for the development of shared knowledge through the web conference, the findings suggest that although knowledge construction was facilitated, it took several months before students began to interact and share ideas with each other. Online writing, while more casual than 'traditional' academic writing, nevertheless 
remained relatively formal and possibly reflected students' perceptions of the task requirements. In response to whether or not students would use computers in their own classrooms, responses were mixed, but generally positive. Some of the implications of this situated evaluation for course designers will be explored in the following section.

\section{Discussion}

The findings from this evaluation suggest several key aspects of computer supported learning and are consistent with those reported elsewhere. Muirhead (2000), citing results from a number of studies in which teachers have used $\mathrm{CMC}$, has described several features for promoting increased online interactivity. Synthesis of his findings fall into two main areas: the role of task structure and organisation, and the role of the teacher. We add that the 'role of task structure' is implies a need to consciously build group dynamics, instead of simply assuming that a sense of group will emerge from the online communication.

\section{Role of group dynamics and task structure in promoting interactivity}

In computer supported teaching, especially in courses where students either do not meet, or meet several months into a course as was the case here, the establishment and maintenance of group dynamics rests with task structures, the language that describes them in course outlines (or other supporting documentation), and the teacher's online use of language. Although some of the participants in this course believed that the face to face meetings were advantageous for them as distance learners, this is not always an option.

One of the first tasks in this course was for students and the instructor to write a self introduction - a standard task in many online courses. However, once students had written their introductions, they did not visit that discussion folder again. The task was inadequate for establishing a sense of group. What Palloff and Pratt (1999) have suggested is that not only do students need to post self introductions, but they need to be required, as part of the task, to comment on what other students have written so as to promote personal interaction. Otherwise, self introductions simply become empty monologues that fail to stimulate the early establishment of a group dynamic. This is particularly critical when students never meet face to face.

Another key aspect of online tasks is that they need to be clearly structured, closely linked into content related issues, and they need to be assessed. As stated earlier, several discussion areas were established for students, but the only ones used extensively were those related to required (assessed) tasks. One of the students summed this up neatly. 
S5: Although the site offered a variety of forums little use was made of any except the 'compulsory' one that was being graded. One of the reasons for this is common to all courses, where, because of time restraints students tend to only do tasks that are graded unfortunately.

Tasks also need to be structured so that they explicitly encourage group collaboration, and there are excellent examples of how, in the 'traditional' classroom, this can be done (Ohio State University, 1998). Course developers need to experiment and adapt collaborative tasks that are known to be effective in face to face mode and, through situated evaluations, learn which approaches are most effective in an online instructional format.

\section{The role of the teacher}

Mason and Weller (2000) in their discussion of the role of the teacher in online courses state that in spite of politicians' and accountants' hopes that online courses will run themselves without the intervention of teachers, successful ones will always rely heavily on the skills, guidance, and support of their instructors. But, how does a teacher manage online learning without becoming completely overwhelmed by it? For example, in this course M. Johnson wrote more than 6,000 words in this one task alone and in another computer supported course, close to 10,000 words. However, those contributions accounted for only about $15 \%$ of the overall writing and according to Ashton, Roberts, \& Teles (2000), this percentage is relatively low; some instructors contribute as much as $50 \%$ of the online exchanges.

Based on this experience, we recommend that as with face to face teaching which typically occurs within clearly defined time slots, the online teacher needs to allocate blocks of time to teaching, and refrain from checking online work outside of those times. Failure to establish clear time limits, with students, colleagues, and self, can lead to unreasonable expectations about the level of a teacher's participation in the course. This idea relates closely to the role of task structure, but from the perspective of the teacher's management of work.

In addition, careful use of language to nurture a collaborative group feeling is another way in which teachers can do online instruction. For example, consistent with previous online courses taught by M. Johnson, 'expressives' and other social speech acts are used frequently to keep the conversation flowing and to maintain a sense of group (see Figure 5). It is also noteworthy that many of the 'administrative/ technical' comments were made in anticipation of assignment deadlines, or to provide 
additional details about course requirements. They were not necessarily made in response to direct questions from students, but instead were intended to prevent potential problems from occurring.

This finding suggests that preparing tutors for online courses needs to include explicit training in the different types of written language that can be used to facilitate and guide students, to sustain a group dynamic, and to provide academic input.

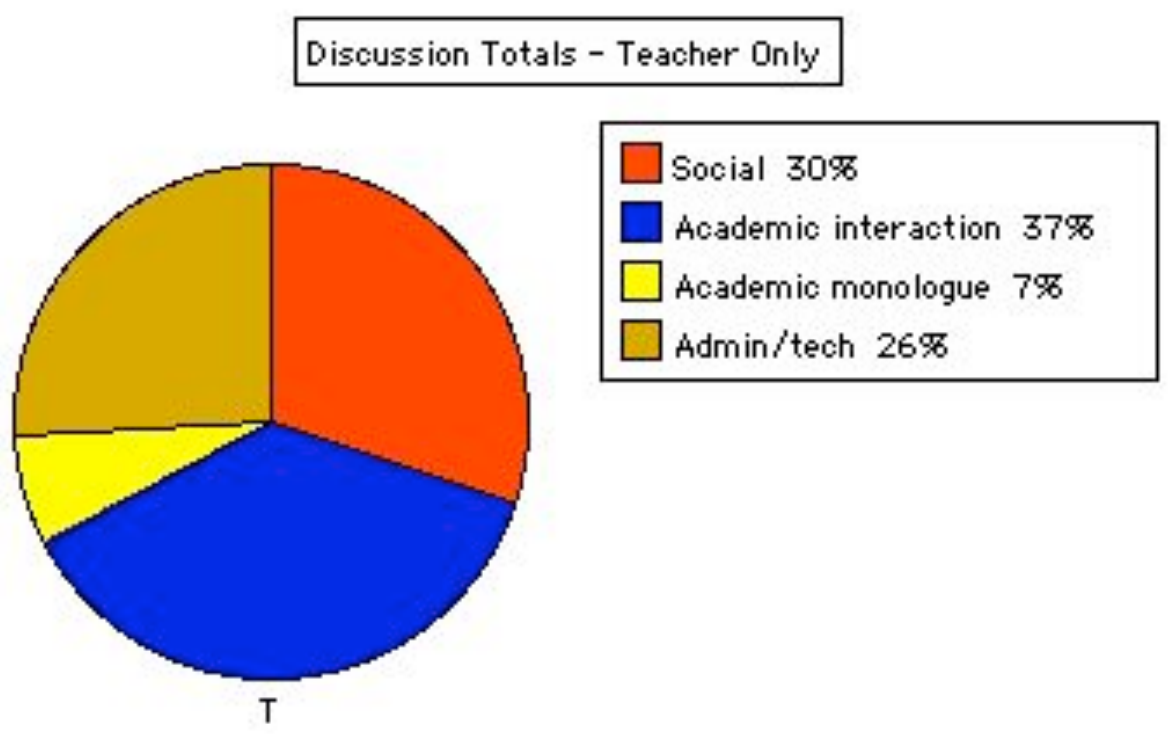

Figure 5: Online discussion patterns of the teacher

In summary, it seems clear that task structure and more specifically, the written language used to describe tasks is a key element in computer supported learning. Similarly, far from having a reduced role in online teaching, instructors need to build careful structures to organise their own work so as to sustain good teaching without becoming overwhelmed. This also suggests use of organisational structures, such as was done here, that place some of the responsibility for task management in the hands of the students. If such work is assessed, then students can assume responsibility for directing group tasks while gaining practice in online classroom management - precisely the types of skills that they will need in their own teaching. 


\section{Conclusion}

We believe that there are some important implications of this study for online teaching and research. Although it may seem obvious to state that we need to rethink our models for how teaching and learning is done in online, or computer supported environments, there is still a lack of clarity about which models should be implemented (Wildner, 2000). In our work, we are moving towards a 'technology infusion' model in which computers are used across all of our courses, not just in the ones specifically addressing issues of electronic literacy. As we are finding, many issues, including the design of appropriate task structures to support constructivist, knowledge building learning environments, the role of the teacher, teacher workload, and access to reliable technical systems support, are all complex yet must be addressed explicitly.

Further, each implementation of computer supported teaching has differences, both subtle and large (Bruce \& Peyton, 1999), and only by understanding the nuances of particular teaching episodes can practitioners begin to realise the potential of technology in the classroom. In the case of this evaluation, inclusion of students' voices enriched what could be learned and is consistent with how we can better understand instructional practice. Transcript analysis on its own would not have provided the types of deeper insights into complex teaching and learning processes that were made possible by inclusion of participants' perspectives. As we continue our research into the development of effective strategies to support both students and teachers in e-learning environments, we plan to include different types of evaluation techniques and data so that we can further refine and streamline our approaches to teaching. Through a gradual building up of knowledge, we may not discover all the answers to structuring online learning environments, but we may at least begin to ask better questions.

\section{References}

Ashton, S., Roberts, T., \& Teles, L. (2000). Investigating the role of the instructor in online collaborative environments. Telelearning NCE - Project 5.25 report. Vancouver: Simon Fraser University [verified 16 Aug 2001] http: / / www.telelearn.ca/g_access/research_projects/index_th5.html

Bruce, B., \& Peyton, J. K. (1999). Literacy development in network-based classrooms: Innovation and realizations. International Journal of Educational Technology, 1(2). [verified 16 Aug 2001] http: / / www.outreach.uiuc.edu/ijet/v1n2/bruce/index.html

Burns, A. (1999). Collaborative action research for language teachers. Cambridge: Cambridge University Press. 
Gebhard, J. G., \& Oprandy, R. (1999). Language teaching awareness: A guide to exploring beliefs and practices. Cambridge: Cambridge University Press.

Hara, N., \& Kling, R. (2000). Students' distress with a web based distance education course. CSI Working Paper [Essay] [verified 16 Aug 2001] http: / www.slis.indiana.edu / CSI / wp00-01.html

Haythornthwaite, C., Kazmer, M. M., Robins, J., \& Shoemaker, S. (2000). Community development among distance learners: Temporal and technological dimensions. JCMC, 6(1). [verified 16 Aug 2001] http: / / www.ascusc.org/jcmc/vol6/issue1/ haythornthwaite.html

Johnson, E. M. (in press). Online web based discussion and language teacher education: The effects of syllabus design on language production. MOSAIC: A Journal for Language Teachers - Special Issue: New Technologies in the Language Learning Classroom.

Kern, R. (2000). Literacy and language teaching. Oxford: Oxford University Press.

Mason, R., \& Weller, M. (2000). Factors affecting students' satisfaction on a web course. Australian Journal of Educational Technology, 16(2), 173-200 [verified 16 Aug 2001] http:/ / www.ascilite.org.au/ajet/ajet16/mason.html

Muirhead, B. (2000). Enhancing social interaction in computer-mediated distance education. Educational Technology and Society, 3(4), 1-11. [verified 16 Aug 2001] http: / / ifets.ieee.org/periodical/vol_4_2000/v_4_2000.html

Ohio State University (1998). Teaching at the Ohio State University: A handbook, 1998. [verified 16 Aug 2001]

http: / / www.osu.edu/education/ftad/Publications/TeachingHandbook

Palloff, R. M., \& Pratt, K. (1999). Building learning communities in cyberspace: Effective strategies for the online classroom. San Francisco: Jossey-Bass Publishers.

Wallace, M. J. (1998). Action research for language teachers. Cambridge: Cambridge University Press.

Wildner, S. (2000). Technology integration into preservice foreign language teacher education programs. CALICO Journal, 17(2), 223-250.

Woods, D. (1996). Teacher cognition in language teaching: Beliefs, decision-making and classroom practice. Cambridge: Cambridge University Press.

\section{E. Marcia Johnson, $P h D$}

Lecturer, Applied Linguistics and CALL

Department of General and Applied Linguistics

The University of Waikato

Private Bag 3105, Hamilton, New Zealand 2001

marcia@waikato.ac.nz

Ann Bishop, Auckland, New Zealand

Anna Holt, Auckland University of Technology, Auckland, New Zealand

Jennifer A. Stirling, University of Otago, Dunedin, New Zealand

Janice Zane, UNITEC, Auckland, New Zealand 